부산 연안의 복합재난 위험성 평가 연구

\title{
A study on risk assessment of complex disasters in Busan coast
}

\author{
황순미·오형민・남수용・강태순
}

(주)지오시스템리서치 연안관리부

\author{
Soonmi Hwang $•$ Hyung-Min Oh $•$ Soo-Yong Nam $・$ Tae-Soon Kang \\ Department of Coastal management, GeoSystem Research Corporation, Gyeonggi, Korea
}

\begin{abstract}
In the vicinity of the coast, there is a risk of complex disasters in which inland flooding, wave overtopping, storm surge, and tsunami occur simultaneously. In order to prepare for such complex disasters, it is necessary to set priorities for disaster preparedness through risk assessment and establish countermeasures. In this study, risk assessment is carried out targeting on Marine city, Centum city, and Millak waterside parks in Busan, where complex disasters have occurred or are likely to occur.

For risk assessment, inundation prediction map constructed by the Ministry of Public Administration and Security in consideration of sea level rise, rainfall and storm surge scenarios and authorized data on social and economic risk factors were collected. The socioeconomic risk factors selected are population, basements, buildings, sidewalks, and roads, and the risk criteria for damage targets are set for each risk factors. And it was assessed considering the maximum inundation depth and maximum flow velocity of the inundation prediction map. Weights for each factor were derived through expert questionnaires. The risk assessment index that was finally evaluated by calculating the risk index for each element and applying weights was expressed as a risk map by different colors into four levels of attention, caution, alert and danger.
\end{abstract}

Keywords : Complex disaster, Flood, Inundation, Risk assessment, Risk map

\section{1. 서 론}

복합재난(Complex Disaster)이란 기후변화에 따른 해수면 상승 - 태풍 - 집중 강우 등 두 가지 이상이 복합적으로 발생 하는 재난 또는 다양한 형태의 단일재난들이 연속 또는 동시 다발적으로 발생하는 재난을 의미한다(Kawata, 2011; Hwang et al., 2020). 기후변화 정부간협의체(IPCC)의 최근 연구결 과에 따르면, 기후변화로 인해 해수면 상승과 해양온난화 속도는 과거에 비하여 빨라지고, 열대 폭풍과 고수온의 빈 도와 강도가 높아졌으며, 연안의 해수면 상승과 고파랑 위 험빈도가 증가할 것이라 전망하였다(IPCC, 2019). 특히, 21 세기말 전 지구 평균 해수면상승은 최대 $1.10 \mathrm{~m}$ 에 달할 수 있으며, 태풍, 집중강우를 동반하여 자연재해에 취약한 연 안 및 해안도시에 큰 피해를 줄 심각한 위험이 있다. 가까운 일본에서는 2018년 태풍으로 인한 폭풍해일로 최대조위를 갱신하였으며 설계외력을 넘는 최악의 상황을 고려하는 방 재·감재로 관점이 전환되었다(Mase et al., 2020). 삼면이 바다로 되어있고, 연안의 인간활동이 잦은 우리나라의 경
우에도, 연안의 재해발생시 복합재난으로 이어질 가능성이 높다. 따라서 이런 예상치 못한 복합재난에 대한 위험성 평 가를 수행하고 그 결과 위험지역으로 선별된 지역에 대해 우선적으로 대응방안 및 대응체계를 구축해야 한다.

연안에서의 복합재난은 태풍, 지진, 이상파고를 동반한 해일, 침수 등이 있으며, 해역별로 발생하는 빈도와 특성이 상이하므로 해역특성에 따라 여러 가지 형태로 발생하는 복합재난에 대한 문제를 해결하기 위한 노력은 과거부터 다양하게 이루어졌다(Kim et al., 2008).

Kim et al.(2018)은 풍수해저감종합계획을 고려하여 해안, 내수, 하천재해 위험지구분석을 통해 복합재난 위험지역을 선정 및 위험 요인을 분석하고 연안구역별 재해영향인자와 재해원인을 분석하였다. Lee et al.(2018)은 국내외 해안가 개발지역에 재해영향을 분석하고 원인별 예방기법을 제시 하였다. Hwang et al.(2020)은 부산마린시티를 대상으로 위 험성 평가를 통해 재난대비 우선순위 선정 및 복합재난 위 험지도 작성을 통한 복합재난의 대응체계를 연구하였다 (Fig. 1). 


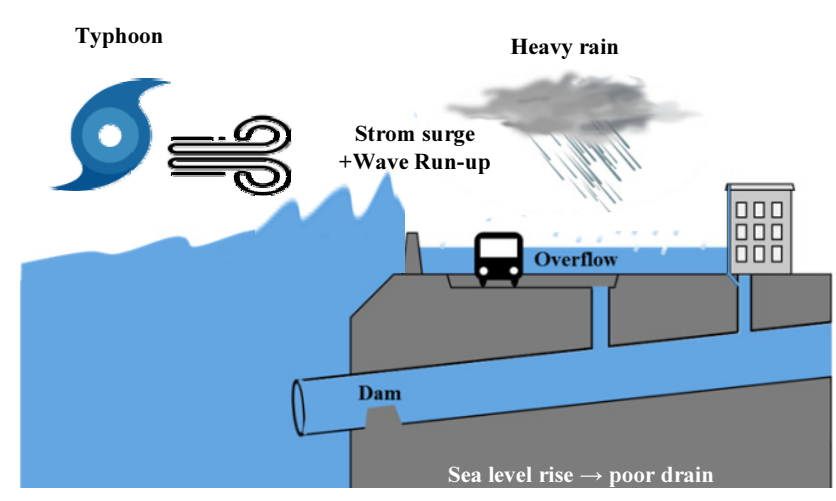

Fig. 1. Conceptual diagram of complex disaster (Hwang et al., 2020)

복합재난으로 인한 침수피해분석은 공학적 측면과 경제 적 측면이 모두 고려되어야 한다. 공학적 과정에서는 수치 모델 시뮬레이션 등을 통해 침수심도를 예측하며, 경제적 과정은 예측된 침수심에 의해 발생되는 각종 경제적 피해 를 계량화하는 과정을 거친다. 최근 각종 통계지표의 개발 과 지리정보시스템(GIS) 등을 통해 모든 정보를 공간정보 화 함으로써 정밀한 분석이 이루어지고 있다. 일본에서는 GIS와 연계한 FDAM(Flood Damage Assessment Methodology) 모형을 개발하였고, 미국은 육군공병단을 중심으로 HEC-FDA 모형을 개발한 바 있다.

우리나라에서는 “치수사업 경제성분석 연구(MCT, 2004)" 를 통해 침수피해를 정량화하였으며, 이후 이를 바탕으로 국내 실정에 부합하는 다수의 연구가 진행되고 있다. 행정 안전부 국립재난안전연구원(NDMI)에서는 2011년부터 풍 수해 취약성 평가시스템 개발 사업의 일환으로 홍수 취약 성지수 기반 평가시스템 개발 과제(NDMI, 2012a)와 지역사 회기반 홍수위험성 평가방법 개선 및 시범적용 과제에서 소하천 위험평가시스템을 구축하였다(NDMI, 2012b). 한편 국립해양조사원(KHOA, 2010)에서는 해안침수예상도 사업 의 일환으로 해일과 파랑을 고려한 침수범람에 대한 연구 를 2009년부터 수행하였다. 2018년부터 행정안전부 국립재 난안전연구원에서 ‘복합재난 리스크 평가기법 개발' 과제 와 ‘해안가 복합재난 위험지역 피해저감 기술개발' 과제가 진행 중이다.

본 연구는 '해안가 복합재난 위험지역 피해저감 기술개 발' 의 주요 연구결과로, 부산의 마린시티, 센텀시티, 수변 공원 인근 3 개 지역에 대해 격자데이터 기반 평가시스템 적용 및 상세단위의 위험성 평가를 수행하였다. 인적 및 물 적 위험성에 대해 사회경제적 위험요소를 채택하여 대리변 수로 고려하고, 각각의 피해대상의 기준에 대해 적용 및 평 가과정을 거쳐 위험지도로 나타내었다.

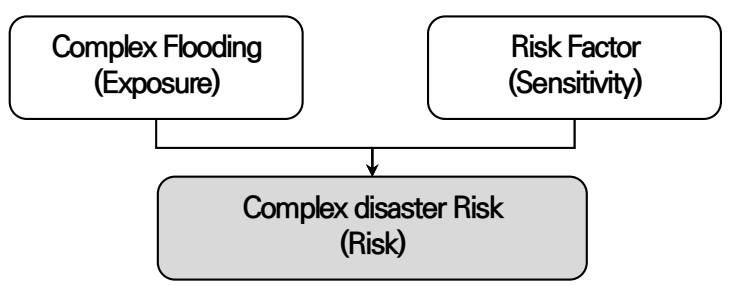

Fig. 2. Framework of risk assessment in this study

\section{2. 평가 방법}

\section{1 평가 개념틀}

본 연구의 사회경제적 요소가 반영된 복합재난 피해위험 성 평가를 수행하기 위해 $\operatorname{IPCC}(2007)$ 의 취약성 개념을 도입 하였다. IPCC(2007)에서 정의한 취약성(Vulnerability) 개념 은 노출(Exposure)과 민감도(Sensitivity) 그리고 적응능력 (Adaptive Capacity)을 고려하여 평가한다. 여기서, 적응능력 은 재해노출 및 민감도에 부정적인 영향을 저감시키는 정 책 및 대책으로 나타낼 수 있다. 그러나 이를 정량화하거나 노출 및 민감도에 따른 잠재적 취약성을 상쇄시키는 지표 로 도출하는데 한계가 있으며, 재해영향을 왜곡시킬 우려 가 있다(MLIT, 2013). 따라서 본 연구에서는 적응능력을 제 외한 노출과 민감도의 함수로 위험성 개념틀을 구성하고 평가하였다(Fig. 2).

노출에는 행정안전부의 복합재난 침수예상도(MOIS, 2020) 의 침수심 및 유속을 고려하고, 민감도에 해당하는 사회 및 경제적 위험요소에 대한 대리변수를 선정한다. 요소별 위 험성 분석을 위해 각각의 평가 기준을 수립하고, 요소별 위 험성 평가를 수행한다. 그리고 전문가 대상 설문조사를 통 해 가중치를 도출하여 요소별 위험성 평가결과에 가중치를 적용하여 복합재난 위험성평가 결과를 도출한다. 결과는 격자에 등급별로 색을 달리 표출하여 시나리오별 복합재난 위험성 평가 지도를 작성한다(Fig. 3).

\section{2 평가 대상지역}

남해안 부산지역의 폭풍(태풍), 월파, 내·외수의 복합재 난이 발생하였거나, 발생 가능성이 높은 지역을 우선 선정 하여 위험성 평가를 수행하였다(Fig. 4). 기존 풍수해저감종 합계획 보고서(2018)를 검토한 결과, 수영구와 해운대구에 대한 하천재해 취약지역 및 내수재해 침수피해 발생이력을 확인하였다. 해운대 마린시티는 해안재해위험지구로 주상 복합구조물이 직접 노출되어 있고, 해일과 고파랑 내습에 따른 위험이 존재한다. 센텀시티는 내수재해 위험지구이며, 지형적으로 매립된 저지대에 해당하여 집중 호우시 빈번한 침수가 발생한다. 민락동 수변공원은 해안재해위험지구로 서 외해측으로 개방되어 파랑이 직접 내습한다. 또한 저지 대 개발로 인한 침수피해 가능성이 높은 지역이다. 


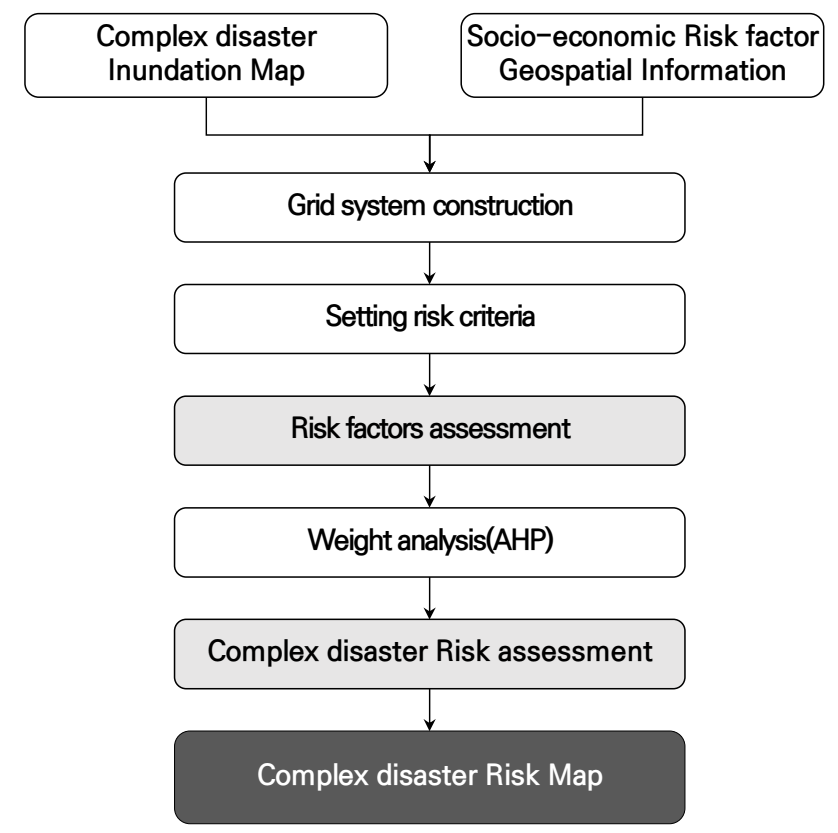

Fig. 3. Flow chart of risk assessment for complex disaster

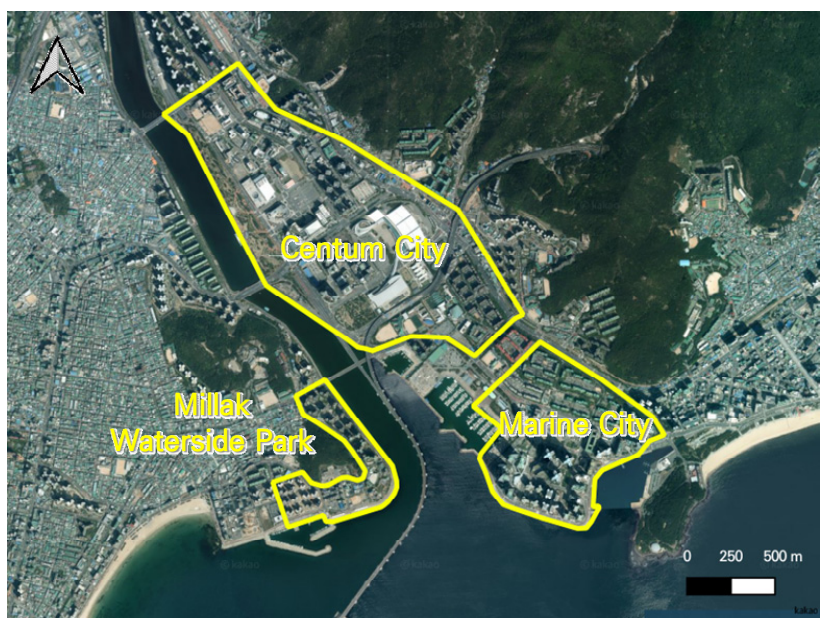

Fig. 4. Target of this study (Marine city, Centum City, Millak Waterside park)

\section{3 평가 격자체계 채택}

복합재난 위험성 평가의 해상도인 격자체계를 결정하였 다. 행정정보의 격자체계 설정 및 공간정보화 기준(국토지 리정보원 예규 제 114 호)을 준용하여 $100 \mathrm{~m}, 50 \mathrm{~m}, 25 \mathrm{~m}$ 등의 격자체계를 구축하고 각각의 침수예상범위를 비교하였으 며, 복합재난 평가의 적정 격자체계를 채택하였다. Fig. 5에 포함된 1 5는 격자당 포함되는 위험요소의 수를 의미하며, $\%$ 는 각 위험요소 수에 대한 포함비율을 의미한다.

$100 \mathrm{~m}$ 격자의 경우 침수예상도의 자료의 해상도가 2 4 m 인 것을 고려하면, 상대적으로 크게 왜곡되는 단점이 있으 며, $25 \mathrm{~m}$ 격자의 경우 격자당 포함되는 위험요소의 수가 적 어 사회경제적 요소를 반영한 복합재난 위험성 평가의 변 별력이 떨어지는 단점이 있다. 따라서 본 연구에서는 변별 성, 가시성, 효율성 등을 고려하여 $50 \mathrm{~m}$ 격자를 채택하였다.

\section{4 평가자료}

위험성 평가를 위해 침수예상도와 사회경제적 위험요소 공간정보를 구축이 필요하다. 먼저 MOIS(2020)의 최대 침 수심 및 최강 유속 자료를 포함하는 침수예상도를 구축하 였다. 구축한 침수예상도는 Table 1에 제시한 바와 같이 총 27개의 시나리오로 구성되어 있다. 기존 연구(MOIS, 2018) 의 결과를 참고하여 2020년 기준, 단기 2050년(30년), 장기 2100년(80년)에 대한 기후변화 시나리오를 구성하였다. 또 한 해안가에서 폭풍해일. 월파, 강우 등의 내/외수 조건이 복합적으로 발생하는 상황을 재현한 것으로 지역별(대상지 역) 방재성능목표 (우수관거 설계빈도 10 30년), 빗물 펌프 장의 설계 빈도(30 50년), 국가하천의 설계 빈도(100 200 년)를 근거로 30 년 $/ 50$ 년/100년 빈도를 설정하였다. Fig. 6은 해수면상승 2100 년기준 100 년빈도 폭풍해일 및 확률강우 시나리오의 최대 침수심과 최강유속자료이다.

사회경제적 위험요소의 평가를 위해 대리변수의 기초자 료(통계청, SGIS, 국토교통부, 국토지리정보원, 해양수산부, 국립해양조사원, 기상청, 지자체 등)를 수집하였다. $\mathrm{OECD}$ (2008)의 종합지수 산정단계 중 ‘자료선택' 요건을 검토하

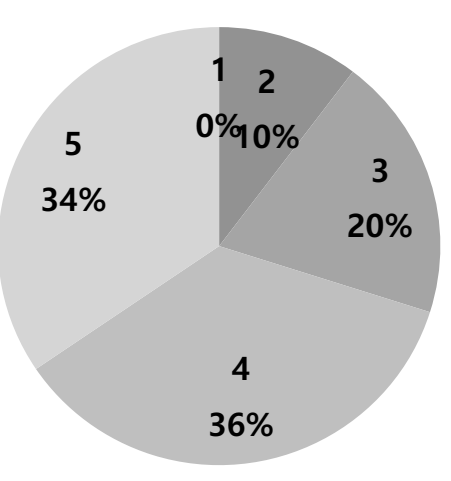

(a) $100 \mathrm{~m}$

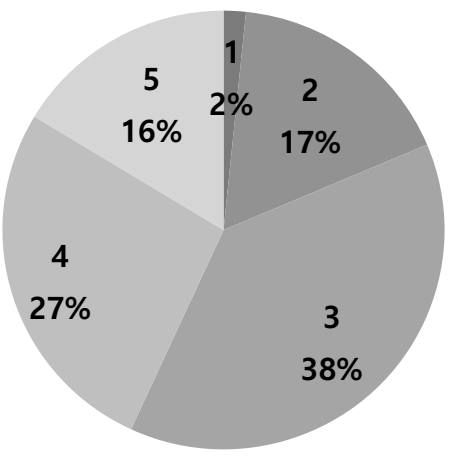

(b) $50 \mathrm{~m}$

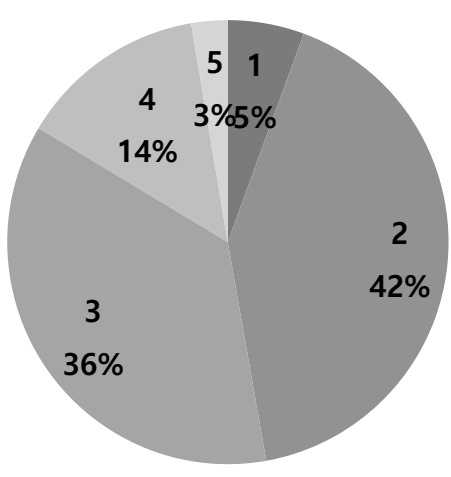

(c) $25 \mathrm{~m}$

Fig. 5. Comparison of the number of risk factors included for each grid size 
Table 1. Complex Disaster Scenarios

\begin{tabular}{c|cc}
\hline Type & Scenario & CASE \\
\hline Tidal level and wave overtopping & $30 / 50 / 100$-year return period & 3 \\
\hline Rainfall & $30 / 50 / 100$-year return period & 3 \\
\hline Climate change & Present / Future $(2050,2100)$ & 3 \\
\hline \multicolumn{2}{r}{ Complex Disaster Scenarios } & 27 \\
\hline
\end{tabular}
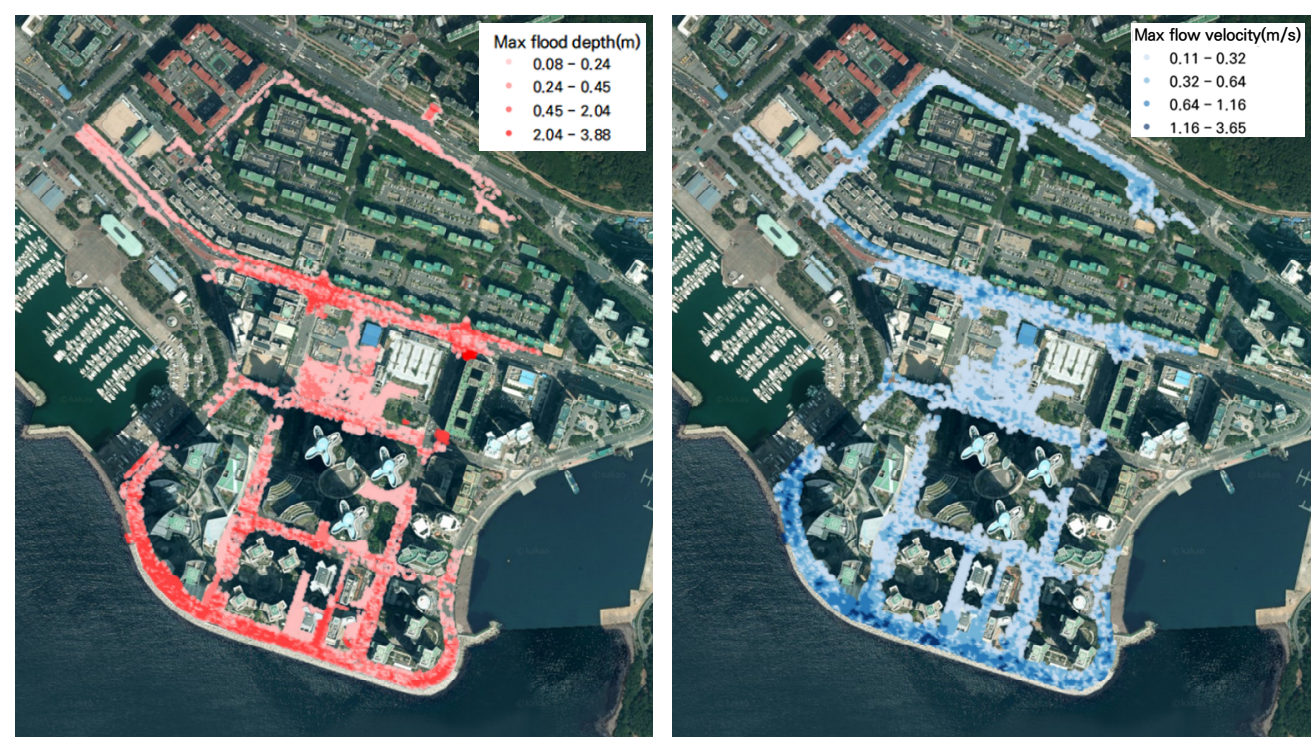

Fig. 6. Example of inundation depth and flow velocity data(MOIS, 2020)

Table 2. Materials and References of risk factors

\begin{tabular}{c|c|c}
\hline Risk factor & Data & Reference \\
\hline Road & (Street name address) Actual width road & Ministry of the Interior and Safety \\
\hline \multirow{2}{*}{ Basement } & Basement information & Self-construction \\
\cline { 2 - 3 } & Digital Topographic Map(Building) & National Geographic Information Institute \\
\hline Sidewalk & Digital Topographic Map(Sidewalk) & National Geographic Information Institute \\
\hline Building & Buildings by usage & Ministry of Land, Infrastructure and Transport \\
\hline Population & Total population $-100 \mathrm{~m}$ grid & National Geographic Information Institute \\
\hline
\end{tabular}

였다. 자료선택 요건은 최신성, 완전성, 신뢰성, 용이성, 정 량성, 주기성, 독립성 7 가지로 각 기준으로 검토하여 최적 의 자료를 선정하였다.

최종 선택된 위험요소는 도로, 지하시설, 인도, 건물, 인구 로 총 5가지이다(Table. 2). 도로, 인도 평가에는 연속수치지 형도의 실폭도로, 인도 자료를 활용하였고, 인구평가에는 국토지리정보원의 $100 \mathrm{~m}$ 격자 총 인구수 자료를 활용하였 다. 지하시설자료는 수치지형도의 건물자료에 있는 건물을 대상으로 현장조사를 통해 지하시설을 파악하여 직접 생산 하였다(Fig. 7). 건물 평가 시에는 건물의 면적, 구조 및 용도 정보를 포함하는 국토교통부의 용도별 건물 자료를 활용하 였다.

\section{5 평가 위험요소 가중치 설정}

최종 선택되어 평가에 고려되는 5가지 위험요소는 모두 동일한 중요도를 가지고 있다고 보기 어려우며, 상대적 중 요도 차이를 가지고 있다. 또한 평가에 사용하는 침수예상 도의 침수심과 침수유속 또한 침수피해 시 같은 영향을 주 는 것으로 보기 어려워 이런 요소 간 상대적 중요도 결정을 위하여 해양 공학 관련 전문가 41 명을 대상으로 설문조사 를 실시하고, 쌍대비교 분석방법인 AHP 분석을 수행하였 다. 설문 분석시에는 신뢰도를 높이기 위하여 설문자가 얼 마만큼의 일관성을 가지고 결과를 적었는가를 보여주는 “일 관성 지수(Consistency Index)"를 적용하였다. 예를 들어 설 문자가 $\mathrm{A}$ 지표는 $\mathrm{B}$ 지표보다 중요하고, $\mathrm{B}$ 지표는 $\mathrm{C}$ 지표보다 

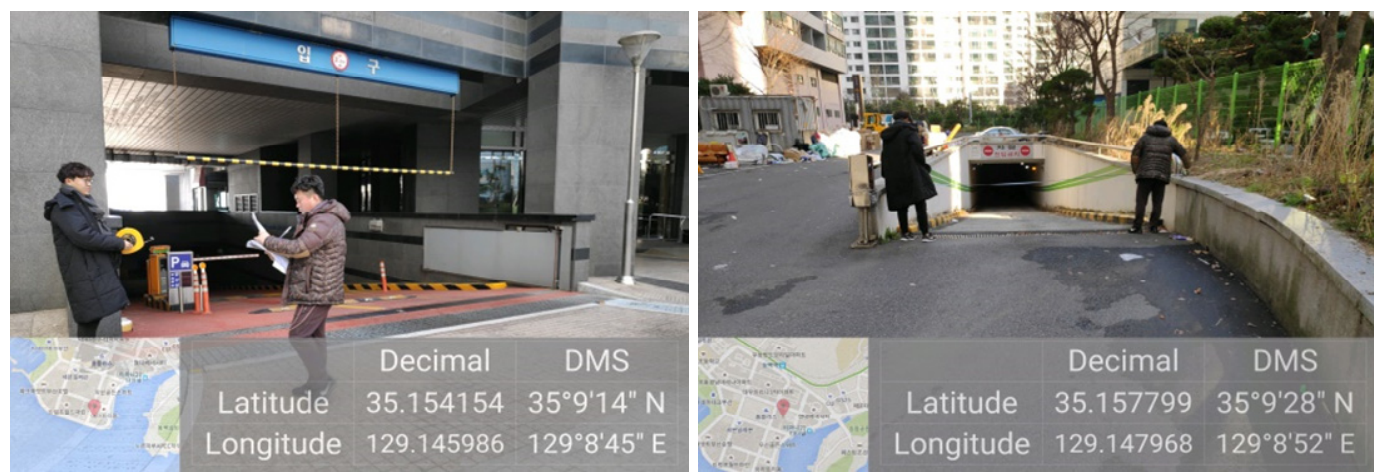

Fig. 7. Self-construction of underground facility data by on-site investigation

Table 3. Flood factors weight analysis result

\begin{tabular}{c|c}
\hline Flood factors & Weight \\
\hline Flood depth & 0.56 \\
\hline Flow velocity & 0.44 \\
\hline
\end{tabular}

Table 4. Risk factors weight analysis result

\begin{tabular}{c|c}
\hline Risk factors & Weight \\
\hline Population & 0.37 \\
\hline Basement & 0.22 \\
\hline Sidewalk & 0.14 \\
\hline Building & 0.14 \\
\hline Road & 0.13 \\
\hline
\end{tabular}

중요하다고 기재하였는데, C지표가 A지표보다 중요하다라 고 기재하면 일관성이 있다고 볼 수 없으며, 그만큼 신뢰성 이 떨어지는 것으로 판단하여 제외하였다.

설문분석결과 침수심 가중치는 0.56 , 침수 유속의 가중치 는 0.44로 산출되었다(Table 3). 그리고 위험요소별 가중치 는 인구 0.37 , 지하시설 0.22 , 인도 0.14 , 건물 0.14 , 도로 0.13 순으로 나타났고 Table 4에 제시하였다.

\section{6 피해대상별 위험 기준 설정 \\ 2.6.1 사람 대상 위험도 기준 설정}

시나리오별 복합재난 침수예상도의 침수심과 침수유속 을 반영하여 사람대상 위험기준을 설정하고자 하였다. Abt et al.(1989)와 Helsinki University of Technology(2000)의 기 존연구에 의하면, 수리실험을 통해 침수심과 유속의 곱의 함수인 경험식을 도출하여 적용성을 검토하였다. 해당 사 례의 경험식은 수심과 유속의 곱에 대한 피실험자의 신장 과 체중의 관계를 나타낸 식으로서 체구별 임계상황을 나 타낼 수 있다. 그러나 유속은 0이지만 침수심이 큰 경우 위 험하다고 판단할 수 있으나, 이 경험식에 의하면 침수심과 유속의 곱은 0 으로 산출되므로 위험성 등급 산정 기준의

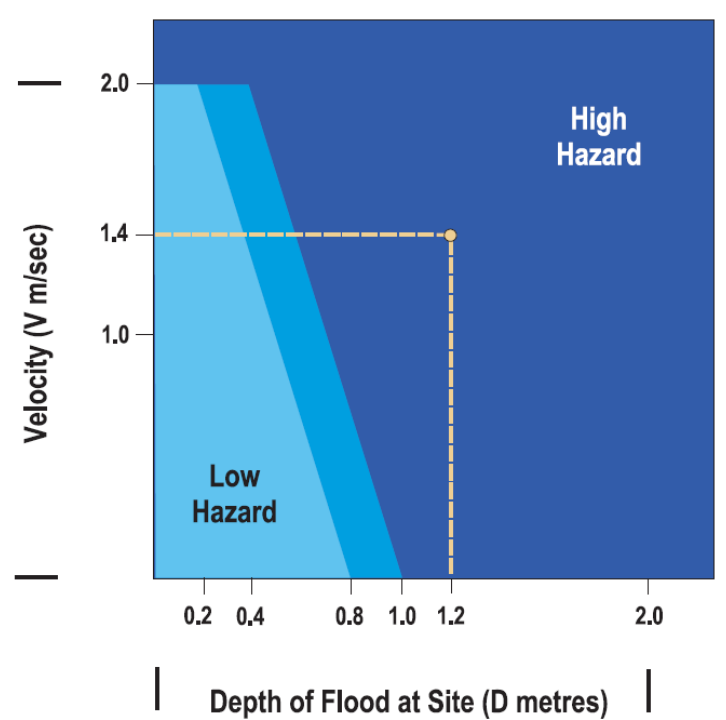

Fig. 8. Provisional Hydraulic Hazard Categories (New South Wales Government, 2005)

반영에는 한계가 있다.

한편, 호주의 범람원 개발 매뉴얼(New South Wales Government, 2005)에서는 침수심과 유속의 상관관계로 시범적인 침수 위험성 단계를 제시한 바 있다(Fig. 8). 본 연구에서는 호주 의 범람원 개발 매뉴얼의 연구결과를 참조하여 사람 대상 위험성 기준인 $X_{S}$ 를 제시하였다. 침수심과 유속을 고려하 기 위하여 침수피해 상황에서의 침수심과 유속의 중요도는 Table 3에 제시된 가중치를 적용하였다.

$$
X_{S}=\text { flood depth } \times \alpha+\text { flow velocity } \times \beta
$$

여기서, $\alpha$ 는 침수심 가중치, $\beta$ 는 유속 가중치이다. 이 가중치를 Eq. (1)에 적용하여 Fig. 8의 기울기를 수정 - 반영 하였으며, 사람대상 위험도 기준을 설정하였다. 사람 위험 도 기준은 위험요소 중 인구 및 인도 평가의 등급구간 설정 에 이용하였다. 


\subsection{2 자동차 대상 위험도 기준 설정}

삼성화재(http://sts.samsungfire.com, 2019)에서는 사고접 수/처리 $\mathrm{DB}$ 를 바탕으로 차량침수사고 발생 및 피해현황과 사고사례를 발표하였다. 엔진 흡입구가 낮은 차량일수록 운행 중 침수피해 위험성이 크며, 운행 중 차량 침수사고는 엔진 흡입구를 통한 빗물 유입이 주된 원인으로 보고한 바 있다. 또한 보험개발원(http://www.kidi.or.kr)에서는 자동차 의 에어클리너가 설치되어 있는 높이보다 수위가 높으면, 에어클리너를 통해 엔진으로 물이 유입되어 시동이 꺼져 피해의 주원인으로 제시하였다(KIDI, 2018). 이에 자동차 종별 에어클리너 설치 높이를 측정한 결과를 살펴보면(Fig. 9, Table 5), 에어클리너 위치는 승용차의 경우 약 $54 \sim 57 \mathrm{~cm}$, 1 톤 트럭의 경우 약 $26-31 \mathrm{~cm}, 2.5$ 톤 트럭은 약 $36 \mathrm{~cm}$, 청소차 는 약 $100 \mathrm{~cm}$, 덤프트럭은 약 $135 \mathrm{~cm}$, 트랙터는 약 $52 \mathrm{~cm}$ 이다. 자동차의 대부분을 차지하는 승용차의 에어클리너 설치 높이 기준 $0.54 \mathrm{~m}$ 이상 시 위험등급으로 판단하고, $0.27 \mathrm{~m}(0.54 / 2)$ 기준으로 주의와 경계 등급을 구분하였다. 설정된 자동차 대상 위험도 기준은 지하시설, 도로 평가의 등급구간 설정 에 이용하였다.

\subsection{3 건물 대상 위험도 기준 설정}

침수시 건물의 피해는 건물의 면적과 구조 및 용도를 고 려한 건물의 가치와 침수심으로 건물 대상 위험도 기준 $X_{B}$ 를 설정하였다. 건물시가 산정방법(NTS, 2019)을 활용하여 건물의 면적과 용도 및 구조를 고려한 건물가치에 침수심
별 피해율을 적용하였다. 건물 기준시가 산정방법에서 건 물신축가격기준액은 $\mathrm{m}^{2}$ 당 710,000 원으로 명시되어 있어 모 든 건물이 동일하므로 계산에서 제외하였다. 그리고 본 연 구의 대상범위는 부산 내 협역을 대상으로 하고 있으므로 위치지수는 모두 동일한 것으로 판단하고 제외, 경과연수 별잔가율은 건물 구조별, 내용연수별로 $0.045 \sim 0.018$ 를 적용 하고 있으나 중요도가 크지 않은 것으로 판단하여 제외하 였다. 따라서 면적, 구조지수, 용도지수에 침수심별 피해율 을 곱하여 Eq. (2)와 같이 건물 대상 위험도 기준 $X_{B}$ 를 설정 하였다. 침수심별 피해율은 USACE (2008)의 주거용과 상 업용을 구분한 자료를 이용하였다(Table 6).

$X_{B}=$ Building area $\times$ Structure index $\times$ Use index $\times$ Damage rate by flood depth Eq. (2)

면적과 구조 및 용도 종류는 용도별 건물 자료(국토교통 부(국가공간정보센터)를 이용하여 분류된 항목에 대해 국 세청(NTS, 2019)의 구조지수 및 용도지수를 참고하여 본 연 구에서 재분류하였다(Table. 7).

\section{7 위험요소별 등급산정 방안 구축}

다섯 가지의 위험요소에 대해 피해대상 위험도 기준을 사 람, 건물, 자동차로 각각 적용하여 각 위험요소를 평가하였 다(Table 8). 인구평가 시 가중치를 적용한 격자내 최대 침 수심 및 유속에 단위격자 당 인구수를 곱하여 0 값을 제외한

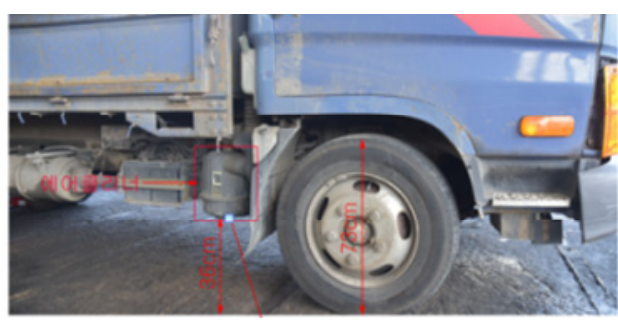

(a) installation air cleaner(2.5T)

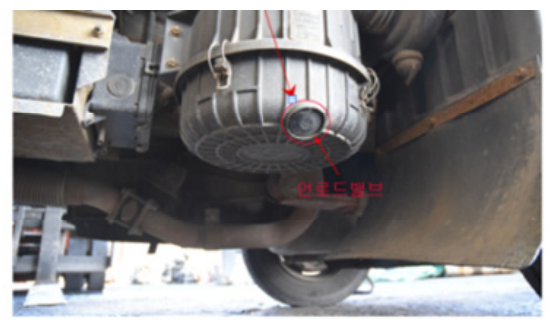

(b) Upload valve(2.5T)

Fig. 9. Risk criteria for automobiles (KIDI, 2018)

Table 5. Front wheel diameter and air cleaner installation height (KIDI, 2018)

\begin{tabular}{c|c|c|c|c|c|c}
\hline \multirow{2}{*}{ Classification } & \multirow{2}{*}{ Car } & \multicolumn{4}{|c|}{ Truck } & \multirow{2}{*}{ Tractor } \\
\cline { 3 - 6 } & & $1 \mathrm{~T}$ & $2.5 \mathrm{~T}$ & Garbage & Dump & \\
\hline Front wheel diameter(cm) & $62 \sim 71$ & 62 & 73 & 84 & 107 & 104 \\
\hline Air cleaner installation height $(\mathrm{cm})$ & $54 \sim 57$ & $26 \sim 31$ & 36 & 100 & 135 & 52 \\
\hline
\end{tabular}

Table 6. Damage rate by flood depth by building use(USACE, 2008)

\begin{tabular}{c|c|c|c|c|c|c|c|c|c|c}
\hline Flood depth $(\mathrm{m})$ & 0.0 & $0.1 \sim 0.3$ & $0.4 \sim 0.6$ & $0.7 \sim 0.9$ & $1.0 \sim 1.2$ & $1.3 \sim 1.5$ & $1.6 \sim 1.8$ & $1.9 \sim 2.1$ & $2.2 \sim 2.4$ & $2.5 \sim$ \\
\hline Residential & 0.08 & 0.22 & 0.32 & 0.40 & 0.47 & 0.53 & 0.59 & 0.63 & 0.71 & 0.73 \\
\hline Commercial & 0.07 & 0.22 & 0.30 & 0.31 & 0.32 & 0.40 & 0.43 & 0.52 & 0.53 & 0.54 \\
\hline
\end{tabular}


3 분위수를 기준으로 등급을 구분하였다. 인도는 가중치를 적용한 격자내 최대 침수심 및 유속을 고려하여 인도를 포 함하는 격자에 평가하였다. 건물평가 시 건물 가치에 건물
주변 $5 \mathrm{~m}$ 범위 최대 침수심을 대상으로 피해율을 고려하여 건물을 포함하는 격자에 평가하였다. 지하시설 평가 시 지 하출입구 반경 $5 \mathrm{~m}$ 범위의 최대 침수심을 대상으로, 현장조

Table 7. Examples of index by structure and use type in building data

\begin{tabular}{|c|c|c|c|}
\hline Structure type & Structure index & Type of use & Use index \\
\hline \multirow{2}{*}{ Lightweight steel structure } & \multirow{2}{*}{75} & House & 100 \\
\hline & & Class 2 neighborhood living facilities & 100 \\
\hline \multirow{2}{*}{ General steel structure } & \multirow{2}{*}{97} & Apartment house & 100 \\
\hline & & Class 1 Neighborhood Living Facility & 100 \\
\hline \multirow{2}{*}{ Block structure } & \multirow{2}{*}{92} & Religious facilities & 100 \\
\hline & & Education and Research Facility & 100 \\
\hline \multirow[t]{2}{*}{ Brick structure } & \multirow[t]{2}{*}{92} & Educational Research and Welfare Facilities & 107 \\
\hline & & Sales facility & 100 \\
\hline Reinforced concrete structure & 100 & Facilities for the elderly & 107 \\
\hline \multirow[b]{2}{*}{ Other masonry structures } & \multirow[b]{2}{*}{100} & Excrement and garbage disposal facilities & 70 \\
\hline & & Warehouse facility & 80 \\
\hline \multirow[b]{2}{*}{ Steel Concrete Structure } & \multirow[b]{2}{*}{115} & Sports facilities & 125 \\
\hline & & Cultural and assembly facilities & 130 \\
\hline \multirow{2}{*}{ Steel Reinforced Concrete Structure } & \multirow{2}{*}{115} & Business facilities & 100 \\
\hline & & Accommodation & 120 \\
\hline
\end{tabular}

Table 8. Risk criteria for each risk factor

\begin{tabular}{|c|c|c|c|c|}
\hline Risk factor & Damage object & Risk criteria & \multicolumn{2}{|r|}{ Risk grade } \\
\hline \multirow{6}{*}{ Population } & \multirow{6}{*}{ Human } & \multirow{6}{*}{$\begin{aligned} X_{P}= & (\text { Flood depth } \times \alpha+\text { Flow velocity } \times \beta) \\
& \times \text { Population in grid } \\
* & =\text { Weight of flood depth, } \\
\beta & =\text { Weight of flow velocity }\end{aligned}$} & Grade & Criteria \\
\hline & & & Attention & $X_{P}=0$ \\
\hline & & & Caution & $0<X_{P} \leq X_{P 1}^{*}$ \\
\hline & & & Alert & $X_{P 1}<X_{P} \leq X_{P 2}^{*}$ \\
\hline & & & Danger & $X_{P 2}<X_{P}$ \\
\hline & & & \multicolumn{2}{|c|}{${ }^{*} X_{P 1}, X_{P 2}=$ Tercile of $X_{P}$} \\
\hline \multirow{5}{*}{ Sidewalk } & \multirow{5}{*}{ Human } & \multirow{5}{*}{$\begin{aligned} X_{S} & =\text { Flood depth } \times \alpha+\text { Flow velocity } \times \beta \\
* \alpha & =\text { Weight of flood depth, } \\
\beta & =\text { Weight of flow velocity }\end{aligned}$} & Grade & Criteria \\
\hline & & & Attention & $X_{S}=0$ \\
\hline & & & Caution & $0<X_{S}<0.448$ \\
\hline & & & Alert & $0.448 \leq X_{S}<0.56$ \\
\hline & & & Danger & $0.56 \leq X_{S}$ \\
\hline \multirow{6}{*}{ Building } & \multirow{6}{*}{ Building value } & \multirow{6}{*}{$\begin{aligned} X_{B}= & \text { Building area } \times \text { Architectural structure } \\
& \times \text { Use } \times \text { Damage rate by flood depth }\end{aligned}$} & Grade & Criteria \\
\hline & & & Attention & $X_{B}=0$ \\
\hline & & & Caution & $0<X_{B} \leq X_{B 1}^{*}$ \\
\hline & & & Alert & $X_{B 1}<X_{B} \leq X_{B 2}^{*}$ \\
\hline & & & Danger & $X_{B 2}<X_{B}$ \\
\hline & & & ${ }^{*} X_{B 1}, X_{B 2}=$ & cile of $X_{B}$ \\
\hline Basement & Car & \multirow{5}{*}{$X_{C}=$ flood depth } & Grade & Criteria \\
\hline \multirow{4}{*}{ Road } & \multirow{4}{*}{ Car } & & Attention & $X_{C}=0$ \\
\hline & & & Caution & $0<X_{C}<0.27 \mathrm{~m}$ \\
\hline & & & Alert & $0.27 \mathrm{~m} \leq X_{C}<0.54 \mathrm{~m}$ \\
\hline & & & Danger & $0.54 \mathrm{~m} \leq X_{C}$ \\
\hline
\end{tabular}


사 결과 지하시설의 대부분이 주차장으로 이용되는 것을 고려하여 자동차 위험도 기준을 적용하여 지하시설 및 해 당 건물을 포함하는 격자에 평가하였다. 마지막으로 도로 평가 시 자동차 위험도 기준을 적용하여 도로를 포함하는 격자에 평가하였다.

각 위험요소별 등급을 산정한 후 복합재난 위험도를 산정 하기 위해서 위험요소 등급을 종합하는 과정을 거친다. Table 4에서 분석된 가중치를 적용하여 요소별 등급을 가중 평균하여 최종 등급을 산출하였다.

\section{3. 평가 결과}

피해대상별 평가기준에 따라 위험요소를 평가하였다. 침 수예상도 총 27 개의 시나리오 중 가장 극한 위험도 시나리 오(2100년기준 해수면상승, 100년빈도 폭풍해일 및 확률강 우)에 대해 위험요소별 평균등급을 Fig. 10에 제시하였다. 지하시설의 경우 각 대상지역에 드물게 분포하고 있어 위
험요소 중 평균등급이 낮게 산출되었다. 특히 민락수변공원 의 경우 세 개 대상지역 중 대상범위의 면적도 좁지만 조사된 지하시설이 7 개에 불과하여 등급이 낮게 산출된 것으로 파악 된다. 인구와 건물의 경우, 등급구분 기준을 3 분위수를 사용 하여 구분하였기 때문에 평균등급의 차이는 크지 않은 것으 로 나타났다. 침수예상도를 살펴보면 대부분 도로(인도)에서 침수가 일어나는 양상을 확인할 수 있어, 도로와 인도의 평균 등급은 세 지역에서 모두 낮지 않음을 확인할 수 있다.

위험요소별 평가등급에 전문가 대상 설문결과인 위험요 소별 가중치를 적용하여 복합재난 위험성 평가등급을 산정 하였다. 침수예상도 총 27 개의 시나리오 중 가장 위험성이 작은 시나리오(현재기준 해수면상승과 30 년빈도 폭풍해일 및 확률강우, Case 1)와 중간 위험도 시나리오(2050년기준 해수면상승과 50년빈도 폭풍해일 및 확률강우, Case 2), 가 장 극한 위험도 시나리오(2100년 기준 해수면상승과 100 년 빈도 폭풍해일 및 확률강우, Case 3)의 3개 시나리오에 대한 위험성 평가결과를 분석하였다.
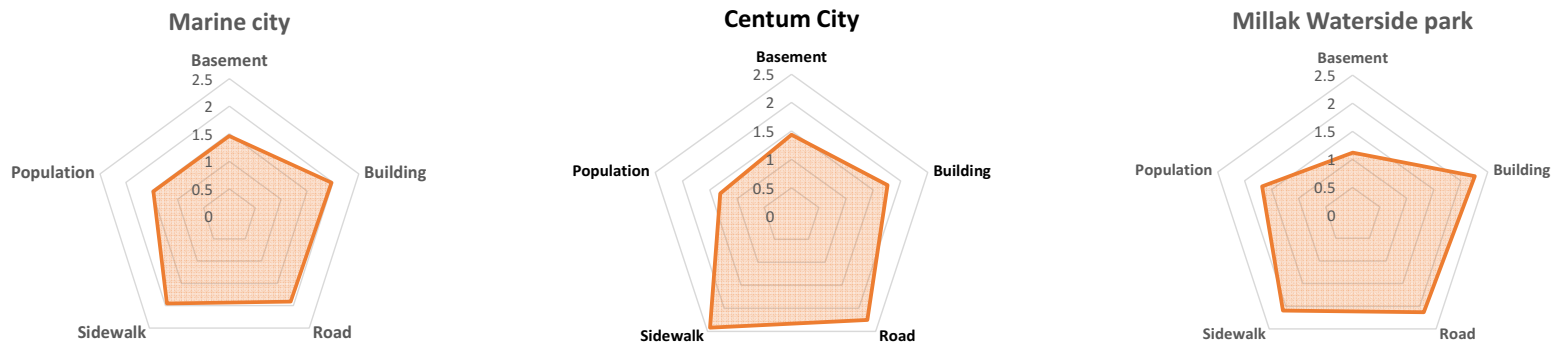

Fig. 10. Average grade by risk factors

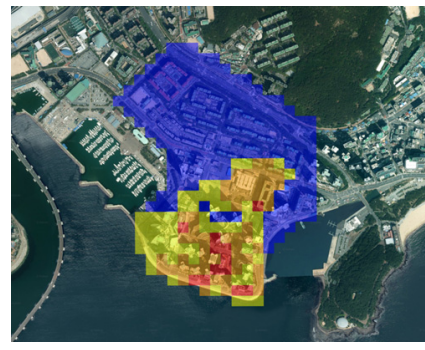

(a) Case 1 : Current sea-level rise, 30-year frequency storm surge and rainfall

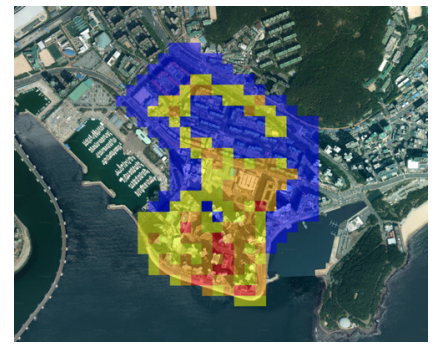

(b) Case $2: 2050$ ' sea-level rise, 50-year frequency storm surge and rainfall

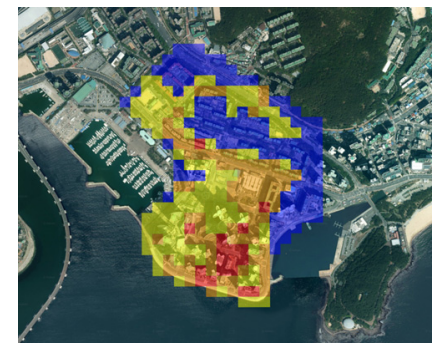

(c) Case $3: 2100$ ' sea-level rise, 100-year frequency storm surge and rainfall

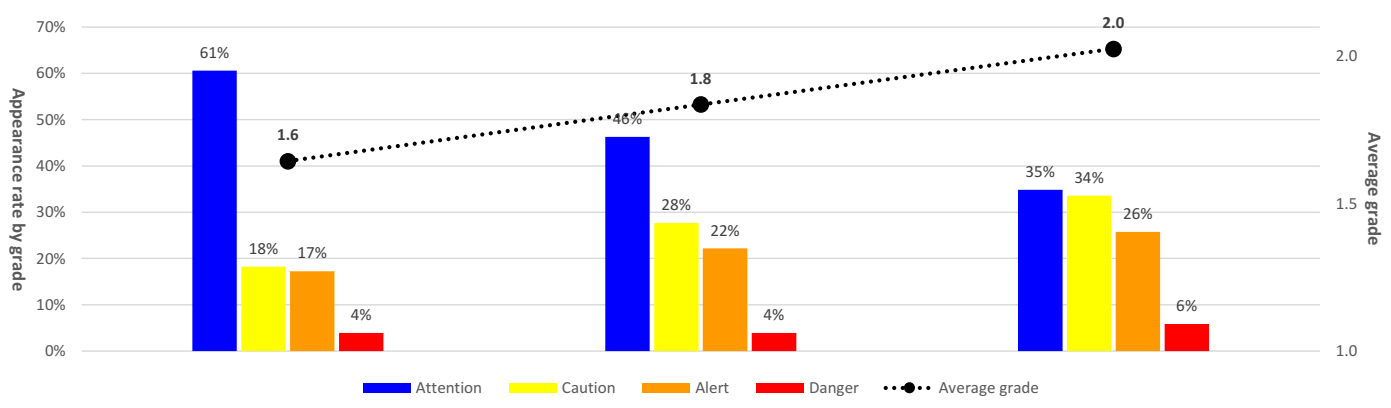

(d) Appearance rate by grade and Average grade

Fig. 11. Complex Disaster Risk Assessment Results in Marine City 


\section{1 부산 마린시티}

평가대상 총 격자수는 307개로 가장 극한상황인 Case 3 시나리오에서 위험등급은 18 개(6\%)격자에서 나타났다(Fig. $11)$. 시나리오간 평균등급이 $1.6,1.8,2.0$ 으로 점진적 상승 경향을 보였고, 극한 시나리오로 갈수록 내수침수로 인한 침수 예상 범위가 넓어짐에 따라 관심 등급 비율은 $61 \%$ 에
서 $35 \%$ 로 감소하였으나 주의, 경계, 위험등급의 비율은 모 두 증가하였다.

\section{2 부산 센텀시티}

평가대상 총 격자수는 603 개로 세 개 대상지역 중 가장 넓다(Fig. 12). Case 3 시나리오에서 위험등급이 $1 \%$ 로 나타

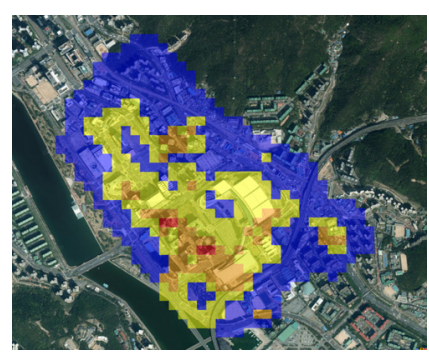

(a) Case 1: Current sea-level rise, 30-year frequency storm surge and rainfall

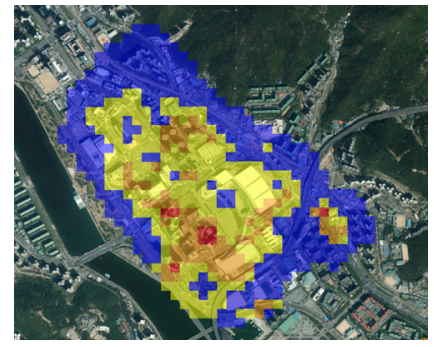

(b) Case $2: 2050$ ' sea-level rise, 50-year frequency storm surge and rainfall

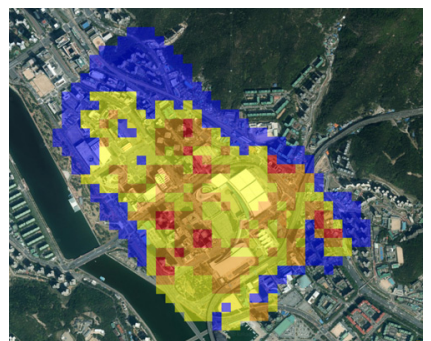

(c) Case $3: 2100$ ' sea-level rise, 100-year frequency storm surge and rainfall

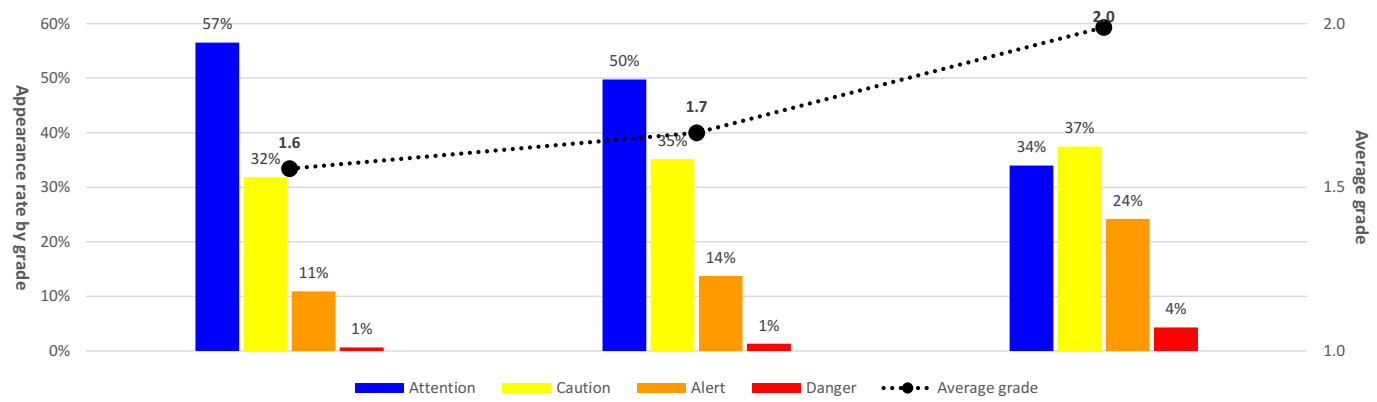

(d) Appearance rate by grade and Average grade

Fig. 12. Complex Disaster Risk Assessment Results in Centum City

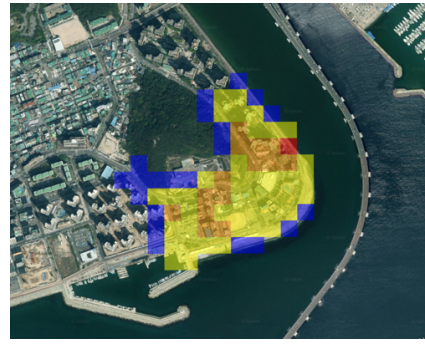

(a) Case 1 : Current sea-level rise, 30-year frequency storm surge and rainfall

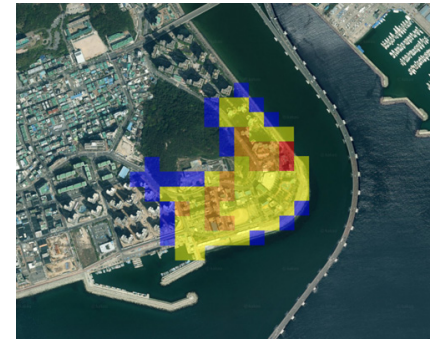

(b) Case $2: 2050$ ' sea-level rise, 50-year frequency storm surge and rainfall

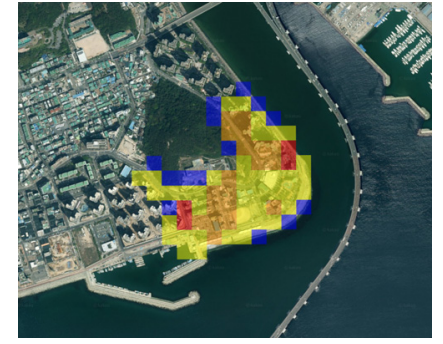

(c) Case $3: 2100$ ' sea-level rise, 100-year frequency storm surge and rainfall

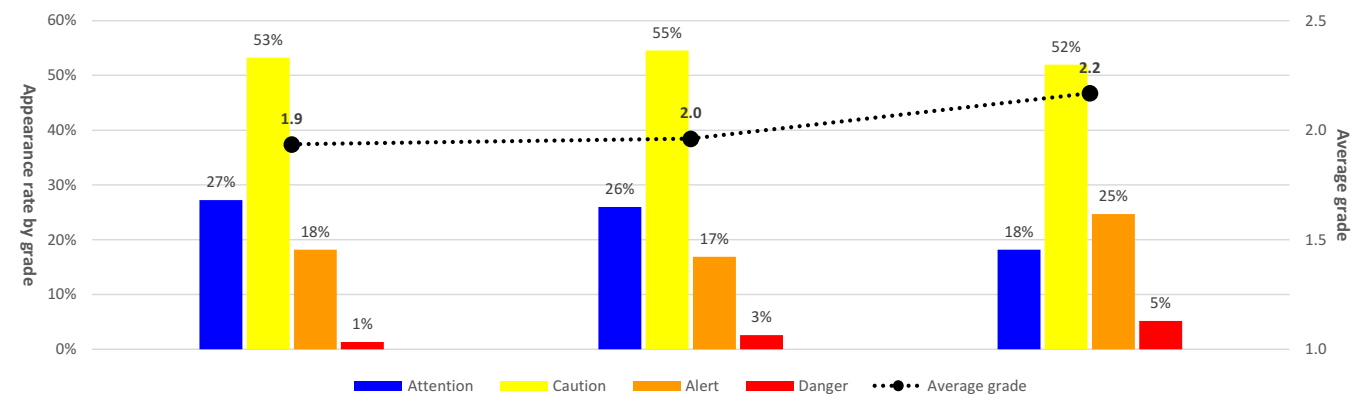

(d) Appearance rate by grade and Average grade

Fig. 13. Complex Disaster Risk Assessment Results in Waterside Park 
난데 비해 시나리오 중 가장 극한상황인 Case 3 시나리오에 서 위험등급은 $4 \%$ 로 증가했다. 이로 인해 Case 2 시나리오 의 평균등급 1.7 에서 Case 3 시나리오의 평균등급이 2.0 으 로 상승하였다. 또한 Case 1과 Case 2 시나리오에서는 침수 되지 않는 지역인 관심등급이 $50 \%$ 이상 나타났다.

\section{3 부산 수변공원}

평가대상 총 격자수는 77 개로 세 개 대상지역 중 가장 좁 다(Fig. 13). 다른 지역과 비교하면 가장 위험성이 작은 Case 1 시나리오에서는 위험등급이 1 개의 격자에서 나온 반면, 가장 극한상황인 Case 3 시나리오에서의 위험 등급은 4개 (5\%)격자에서 나타났다. 세 가지 시나리오 모두에서 주의, 경계, 위험 등급이 $70 \%$ 가 넘게 나타나 평가대상 범위에는 침수가 대부분에서 예상된다.

\section{4. 결 론}

본 연구에서는 행정안전부의 내수와 외수의 복합재난 침 수예상도 최대 침수심 및 유속 자료와 사회경제적 위험요 소 자료를 이용하여 복합재난 위험성 평가를 수행하였다. 위험요소를 인구, 지하시설, 건물, 도로, 인도 다섯 가지로 선정하여 피해대상별 위험도 기준을 설정하여 평가를 수행 했다. 기후변화로 인한 해수면 상승을 고려하고 빈도별 강 우 및 해일 시나리오에 대해 위험요소별 가중치를 적용하 여 위험요소 간 가중평균한 평가결과를 나타냈다.

각 시나리오의 침수예상도를 살펴보면, 위험요소 중 도로 (인도) 위치에서 주로 침수가 일어나는 것으로 확인하였다. 이는 도시계획상 도로의 역할이 차량의 이동뿐만 아니라 강우 배수의 역할을 함께 하며 상대적으로 낮은 고도에 위 치하고 있기 때문이다. 또한 부산의 경우 상대적으로 경사 도가 높기 때문에 침수피해의 양상은 계곡이나 고밀도 도 시화지역의 하천에서 발생하는 돌발홍수(Flash flood)의 경 향이 나타난다. 따라서 본 연구 대상지역인 상대적으로 고 도가 낮은 매립지인 마린시티와 센텀시티, 해안주변인 수 변공원 지역은 투과성 아스팔트, 지하홍수조절지 등의 구 조적 대책과 갑작스런 침수에 대비한 경보시스템 및 대피 체계 등의 비구조적 대책이 필요하다. 본 연구에서 사회경 제적 위험요소별 평가결과와 이 결과를 종합한 복합재난 위험성평가결과를 다방면으로 분석하여 복합재난 침수피 해에 대한 대응체계를 수립할 수 있다. 향후 연구에서는 위 험요소의 다각화를 통해 피해위험 재현의 정확도를 높이 고, 사람 대상 위험도 기준 설정시 본 연구에서 고려하고자 하였으나 한계가 있었던 사람의 신장 및 체중을 고려할 수 있는 방안 마련이 필요하다. 또한 인구 다음으로 가중치가 높게 나타난 지하시설물 침수의 피해대상 및 평가 기준에 대한 연구를 고도화 할 필요가 있다.

\section{감사의 글}

본 연구는 행정안전부 극한 재난대응 기술개발사업 '해안 가 복합재난 위험지역 피해저감 기술개발(2018-MOIS31-008)' 과제의 지원으로 수행되었습니다.

\section{References}

Abt, S. R., Wittler, R. J., Taylor, A. and Love, D. J. (1989). "Human stability in a high flood hazard zone." American Water Resources Association, Vol. 25, No. 4, pp. 881-890.

Helsinki University of Technology (2000). "The use of physical modes in dam-break flood analysis Final report of Helsinki University of Technology."

Hwang, S.-M., Oh, H. S., Nam, S. Y. and Kang, T. S. (2020). "Coastal complex disaster risk assessment in Busan Marine City." The Korean Society of Marine Environment \& Safety, Vol. 26, No. 5, pp. 506-513 (in Korean).

IPCC (Intergovernmental Panel on Climate Change) (2007). Climate Change 2007 - Impact, Adaptation and Vulnerability. Cambridge university press.

IPCC (Intergovernmental Panel on Climate Change) (2019). Special Report on the Ocean and Cryosphere in a Changing Climate.

Kawata, Y. (2011). "Downfall of Tokyo due to Devastating Compound Disaster.” Journal of Disaster Research, Vol. 6, No. 2, pp. 176-184.

KHOA (Korea Hydrographic and Oceanographic Agency) (2010). Production and distribution of coastal inundation prediction map. Final Report (in Korean).

Kim, B. R., Lee, S. H., Oh, K. R. and Sim, O. B. (2018). “Analysis of Disaster-Influenced Factors and Causes in Compound Disaster Districts in Coastal Areas." J. Korean Soc. Hazard Mitig, Vol. 18, No. 7, pp. 621-629 (in Korean).

Kim, K. H., Yoo, H.-S. and Jung, E. J. (2008). "Disaster Overall Prevention System for Beach Erosion and its Applications." Journal of Korean Society of Coastal and Ocean Engineers, Vol. 20, No. 6, pp. 602-610 (in Korean).

Korea Insurance Development Institute (2018). Driving in flooded areas, be extra careful, KIDI, Seoul, http://www.kidi.or.kr (last date accessed: 28 Jun 2018).

Lee, S. H., Kim, B. R., Im, J. H., Oh, K. R. and Sim, W. B. (2018). "A Study on the application of Coastal Disaster Prevention Considering Climate Change." J. Climate Change Research, Vol. 9, No. 4, pp. 369-376 (in Korean).

Mase, H., Kim, S., Hasegawa, M., Jeong, J. H. and Yoon, J.-S. (2020), "Development of Wave Overtopping-Overflow Transition 
Model Based on Full-scale Experiments." Journal of Ocean Engineering and Technology, Vol. 34, No. 2, pp. 128-135.

MCT (Ministry of Construction and Transportation) (2004). "Study on the economic analysis in flood control projects : Multi-dimensional flood damage analysis." (in Korean).

MLIT (Ministry of Land, Infrastructure and Transport) (2013). "Urban Climate Change Disaster Vulnerability Analysis Manual." (in Korean).

MOIS (Ministry of the Interior and Safety) (2018). "Development of complex cause flood vulnerability assessment technology and research on countermeasures for adaptation to climate change on coastal city." Final Report (in Korean).

MOIS (Ministry of the Interior and Safety) (2020). "Development of mitigation technology for hazardous area due to complex disasters coastal zone." Final Report (in Korean).

NTS (National Tax Service) (2019). "Explanation of the method of calculating the standard market price of a building." (in Korean).

NDMI (National Disaster Management Research Institute) (2012a).
"Development of Assessment System for Flood Vulnerability Index. Final Report." (in Korean).

NDMI (National Disaster Management Research Institute) (2012b).

"Trial and Improvement of Community-based Flood Risk Assessment Methods. Final Report." (in Korean).

New South Wales Government (2005). “Floodplain Development Manual."

OECD (Organization for Economic Co-operation and Development) (2008). "Handbook on Constructing Composite Indicators."

Samsung traffic safety research institute (2019). Samsung Fire \& Marine Insurance "Damage of 8.3 million won per car flood... Because of a lot of scrap cars", Samsung Fire \& Marine Insurance, Seoul, http://sts.samsungfire.com (last date accessed: $14 \mathrm{Jul}$ 2019).

USACE (U.S. Army Corps of Engineers) (2008). “Final Economic Reevaluation Report." American River Watershed Project, California. Folsom Dam Modification and Folsom Dam Raise Projects. Appendix D - Economics. U.S. Army Corps of Engineers. 